\title{
STUDY OF THE ANTICONVULSANT ACTIVITY OF ETHANOLIC EXTRACT OF ROOT OF ACORUS CALAMUS IN ALBINO RATS
}

\author{
SHIPRA KAUSHIK ${ }^{1 *}$, KALPANA GOHAIN ${ }^{2}$ \\ ${ }^{1}$ Department of Pharmacology, GS Medical College and Hospital, Pilkhuwa, Hapur, Uttar Pradesh, India. ${ }^{2}$ Department of Pharmacology, \\ Assam Medical College and Hospital, Dibrugarh, Assam, India. Email: shipra014@gmail.com
}

Received: 08 August 2018, Revised and Accepted: 12 September 2018

\section{ABSTRACT}

Objective: Root of Acorus calamus has been traditionally used as an anticonvulsant. The aim of the study is to assess the anticonvulsant activity of ethanolic extract of A. calamus (EEAC) by maximal electroshock seizure (MES) and pentylenetetrazol (PTZ)-induced seizure models on albino (Wistar strain) rats.

Methods: Albino rats were taken and divided into five groups, each consisting of five rats both for MES and PTZ model. One group was used as control (normal saline $10 \mathrm{ml} / \mathrm{kg}$ ), one as standard (phenytoin in MES model/diazepam in PTZ model), and three groups for the test drug (EEAC in the doses of 100, 200, and $400 \mathrm{mg} / \mathrm{kg}$ ). In MES model, maximal electrical shock of $150 \mathrm{~mA}$ was passed for $0.2 \mathrm{~s}$ through earlobe electrodes after $30 \mathrm{~min}$ of giving the drugs and normal saline. Different stages of convulsions were noted down along with time spent by the animal in each phase of convulsions. In PTZ model, PTZ was injected 30 min after giving the drugs and normal saline, and onset of action and severity of convulsions were noted. Data were statistically analyzed by one-way analysis of variance followed by multiple Dunnett's test.

Results: EEAC dose dependently reduced the duration of tonic hind limb extension in MES model, and there was increase in latency and occurrence of convulsions in PTZ model.

Conclusion: EEAC has anticonvulsant activity.

Keywords: Anticonvulsant, Maximal electrical shock, Pentylenetetrazol, Acorus calamus.

(C) 2019 The Authors. Published by Innovare Academic Sciences Pvt Ltd. This is an open access article under the CC BY license (http://creativecommons. org/licenses/by/4. 0/) DOI: http://dx.doi.org/10.22159/ajpcr.2019.v12i1.29004

\section{INTRODUCTION}

Epilepsy is a disease of the brain characterized by atleast two unprovoked (or reflex) seizures occurring more than $24 \mathrm{~h}$ apart [1]. In epilepsy, there is predisposition to generate epileptic seizures [2]. Seizures occur due to abnormal excessive or synchronous neuronal activity in the brain and are associated with alterations in electrographic pattern, consciousness, sensation, and behavior. Secondary epilepsy may result from various insults such as anorexia, trauma, tumors, metabolic abnormalities, neurotoxicity, drug withdrawal, and encephalitis [3].

Although lots of antiepileptic drugs are available in the market, almost $33 \%$ of patients continue to present seizure [4]. There comes the importance of animal models, especially newer models that can model epilepsy in a more realistic way. However, there is a growing concern that conventional tests (maximal electroshock seizure [MES] and Sc. PTZ) identify only those drugs which have similar characteristics with existing drugs, and these methods may fail to identify agents acting by novel mechanisms [5].

The importance of traditional system of medicine and certain medicinal practices has now been recognized worldwide. Today, it is required to have an intelligent and pragmatic approach to evaluate selective drugs of herbal origin [6].

Acorus calamus is commonly known as sweet flag in English and vasa/bach in Hindi. A. calamus is a source of essential oil, which is responsible for the medicinal and insecticidal properties. It is reported to possess insecticidal, lucicidal, anti-inflammatory, antibacterial, antiulcer radioprotective, antispasmodic, bronchodilatory, glucosidase inhibitory, insulin sensitizing, antiepileptic, anticholinesterase, larvicidal, antibacterial, mutagenic, anticonvulsant, neuroleptic, smooth muscle relaxant, and smooth muscle stimulant activity [7].
The roots and rhizomes of this plant have been used in the Indian systems of medicine for 100 years. It is used in Ayurveda medicine on a regular basis for the treatment of insomnia, melancholia, neurosis, epilepsy, hysteria, loss of memory, and remittent fevers [8].

Different parts of the plant showed the presence of large number of phenylpropanoids, sesquiterpenes, monoterpenes, xanthone glycosides, flavones, lignin, lignans, steroids, and inorganic constituents. Alcoholic extracts of the triploid A. calamus were characterized by a higher percentage of beta-asarone (11\%), which was the main compound [9].

A. calamus has been used for a long time in traditional medicine as a remedy for pain, convulsions, inflammation, and ulcer. Drugs acting in the central nervous system were among the first to be discovered by the primitive human and are still the most widely used group of pharmacological agents. The central nervous system (CNS) acting drugs are invaluable therapeutically because they can produce specific physiological and psychological effects. From the vast array of materia medica of the indigenous system so many plants have been reported to have activity against CNS disorders and thus act as very useful remedies for the alleviation of human suffering [10].

In spite of traditional use, pharmacology of its different parts has not yet been explored scientifically. As such, the present investigation was carried out to evaluate the antiepileptic activity of the ethanolic extract of root of A. calamus (EEAC) in experimental animal models.

\section{METHODS}

This study has been approved by IEAC, Assam Medical College, Dibrugarh. Certificate no. being AMC/EC/PG/2013/11718 dated 06/09/2013. 


\section{Plant authentication}

A. calamus root was collected from the PG hostel campus of Assam Medical College, Dibrugarh, and identified by Dr. L.R. Saikia, Reader, Department of Life Sciences, Dibrugarh University, Dibrugarh, Assam, with identification voucher number DUL. Sc.457.

\section{Preparation of plant extract}

The required amount of root of A. calamus was collected and dried at room temperature. The dried roots were ground into powder separately. Sufficient amount of powdered roots was moistened with $95 \%$ ethyl alcohol and allowed to remain for $6 \mathrm{~h}$ in a percolator. When the liquid began to drop from the percolator, the orifice was closed and the content was allowed to macerate for $24 \mathrm{~h}$. After $24 \mathrm{~h}$, it was allowed to percolate slowly, a rate not exceeding $1 \mathrm{ml} / \mathrm{min}$ and the solution was collected in Petri dishes. Alcohol was allowed to evaporate at room temperature. When the extract got completely dried, it was scrapped out, weighed, and stored, and the yield at the end of extraction was found to be $80 \mathrm{~g}$ [11].

\section{Drugs}

Phenytoin obtained from Zydus Cadila Healthcare Limited, Diazepam obtained from Ranbaxy Laboratories, New Delhi, and pentylenetetrazol (PTZ) obtained from Sigma-Aldrich, India, Bangalore.

\section{Animal}

Healthy Albino rats (Rattus norvegicus) weighing from 150 to $250 \mathrm{~g}$ of either sex were taken from Central Animal House, Assam Medical College (registration no. 634/02/a/CPCSEA dated 19/05/02). The animals were housed in standard cages and maintained under normal room temperature. The rats were maintained on standard animal diet of Bengal gram, wheat, maize, and carrot in sufficient quantity for the entire period of the experiment. Water was given ad libitum during the entire period of the experiment.

\section{Acute oral toxicity studies}

Acute oral toxicity test was done according to the OECD guidelines 425 [12]. Albino rats of either sex were used. A total of five animals were used. After overnight fasting, they received a single oral dose (2000 mg/kg body weight) of EEAC. Then, food was withheld for further 3-4 h. Animals were observed individually at least once during the first $30 \mathrm{~min}$ after dosing, periodically during the first $24 \mathrm{~h}$ (with special attention during the first $4 \mathrm{~h}$ ) and daily thereafter for 14 days. At the end of the study, the animals were observed for general toxic signs, morphological behavior, and mortality.

\section{Experimental design}

\section{MES model}

A total of 25 Albino rats were taken and divided into four groups, five rats in each and treated as follows:

1. Control - received normal saline $(10 \mathrm{ml} / \mathrm{kg})$ intraperitoneal (i.p.)

2. Test 1 - received EEAC $100 \mathrm{mg} / \mathrm{kg}$ i.p.

3. Test 2 - received EEAC $200 \mathrm{mg} / \mathrm{kg}$ i.p.

4. Test 3 - received EEAC $400 \mathrm{mg} / \mathrm{kg}$ i.p.

5. Standard drug - received phenytoin $25 \mathrm{mg} / \mathrm{kg}$ i.p. [13]
Each animal was properly held and earlobe electrodes were placed on the earlobes and current of $150 \mathrm{~mA}$ was passed for $0.2 \mathrm{~s}$. Different stages of convulsions were noted down, along with the time spent by the animal in each phase. The same procedure was repeated with other animals of control group. The current was passed $30 \mathrm{~min}$ after i.p. injection of normal saline. For test groups, the same procedure was repeated for three different doses $(100,200$, and $400 \mathrm{mg} / \mathrm{kg})$ of EEAC.

Phenytoin was also injected i.p. to all the five rats. After $30 \mathrm{~min}$, the animals were subjected to electroconvulsions.

This model identifies those compounds, which prevent seizure spread [14].

The reduction in time or abolition of tonic extensor phase of MES - convulsions was recorded for all the animals [15].

\section{PTZ model}

It is reported to act through benzodiazepine receptor mechanisms in the brain.

A total of 25 albino rats were taken and divided into four groups, five rats in each and treated as follows:

1. Control - received normal saline $(10 \mathrm{ml} / \mathrm{kg})$ i.p.

2. Test 1 - received EEAC $100 \mathrm{mg} / \mathrm{kg}$ i.p.

3. Test 2 - received EEAC $200 \mathrm{mg} / \mathrm{kg}$ i.p.

4. Test 3 - received EEAC $400 \mathrm{mg} / \mathrm{kg}$ i.p.

5. Standard drug - received diazepam $4 \mathrm{mg} / \mathrm{kg}$ i.p.

Normal saline, test drugs, and diazepam were injected i.p. to the animals, and after $30 \mathrm{~min}$, PTZ (60 mg/kg) [16] was injected subcutaneously to these animals and the onset of action (indicated by Straub's tail, jerky movements of whole body and convulsions) and severity of convulsions due to the drug were noted.

Either delay or complete abolition of convulsions in rats treated with diazepam and EEAC was noted [17].

\section{Statistical analysis}

The statistical significance between groups was analyzed separately using one-way analysis of variance (ANOVA) followed by Dunnett's multiple comparison test. The statistical significance was expressed by $\mathrm{p}$ values, as mentioned in the tables. $\mathrm{p}<0.05$ was considered as statistically significant.

\section{RESULTS}

Acute toxicity test- there was no mortality and no signs-symptoms of toxicity reported among the animals up to $2000 \mathrm{mg} / \mathrm{kg}$. Hence, the $\mathrm{LD}_{50}$ was calculated $>2000 \mathrm{mg} / \mathrm{kg}$ body weight.

In MES model, although the test groups did not abolish the extensor phase completely like phenytoin, there was significant $(<0.01)$ reduction in the duration of the tonic hind limb extensor phase in a dose-dependent manner. All the rats under the study recovered without any deaths [Table 1].

Table 1: Effect of EEAC on extensor phase of convulsion induced by MES model in albino rats

\begin{tabular}{lllll}
\hline Group & Treatment $(\mathbf{m g} / \mathbf{k g})$ & Number of rats & Hind limb extension (seconds \pm SEM) & Recovery \\
\hline Control & Normal saline $10 \mathrm{ml} / \mathrm{kg}$ & 5 & $11.87 \pm 0.38$ & $\mathrm{R}$ \\
Test 1 & EEAC 100 & 5 & $5.26 \pm 0.16^{\mathrm{a}}$ & $\mathrm{R}$ \\
Test 2 & EEAC 200 & 5 & $3.94 \pm 0.018^{\mathrm{a}}$ & $\mathrm{R}$ \\
Test 3 & EEAC 400 & 5 & $2.14 \pm 0.108^{\mathrm{a}}$ & $\mathrm{R}$ \\
Standard & Phenytoin 25 & 5 & $0^{\mathrm{a}}$ & $\mathrm{R}$ \\
One-way ANOVA & $\mathrm{F}$ & & 427.6 & \\
& $\mathrm{df}$ & & 4,16 & \\
& $\mathrm{P}$ & & $<0.01$ & \\
\hline
\end{tabular}

$\mathrm{n}=5$ in each group; all the values were expressed in mean \pm SEM. ${ }^{\mathrm{a}} \mathrm{p}<0.01$ is significant when compared with control (ANOVA followed by Dunnett's multiple comparison test), EEAC: Ethanolic extract of A. calamus, MES: Maximal electroshock seizure, Acorus calamus: A. calamus 
Table 2: Effect of EEAC on duration of convulsion in PTZ-induced seizure model in albino rats

\begin{tabular}{|c|c|c|c|c|c|c|}
\hline Group & $\begin{array}{l}\text { Number of } \\
\text { animals }\end{array}$ & $\begin{array}{l}\text { Treatment } \\
(\mathrm{mg} / \mathrm{kg})\end{array}$ & $\begin{array}{l}\text { Latency } \\
(\text { sec } \pm \text { SEM) }\end{array}$ & $\begin{array}{l}\text { Number of } \\
\text { convulsions }\end{array}$ & $\begin{array}{l}\text { Average duration of convulsion } \\
\text { (sec } \pm \text { SEM) }\end{array}$ & Recovery \\
\hline Control & 5 & $\begin{array}{l}\text { Normal } \\
\text { saline } \\
10 \mathrm{ml} / \mathrm{kg}\end{array}$ & $558 \pm 35.41$ & $1.6 \pm 0.24$ & $13.20 \pm 0.86$ & $\mathrm{R}$ \\
\hline Test 1 & 5 & EEAC 100 & $1194 \pm 42.65^{a}$ & 1 & $9.68 \pm 0.44^{\mathrm{a}}$ & \\
\hline Test 2 & 5 & EEAC 200 & $1434 \pm 46.75^{\mathrm{a}}$ & 1 & $7.48 \pm 0.22^{\mathrm{a}}$ & $\mathrm{R}$ \\
\hline Test 3 & 5 & EEAC 400 & $1998 \pm 35.97^{\mathrm{a}}$ & 1 & $5.4 \pm 0.27^{a}$ & $\mathrm{R}$ \\
\hline Standard & 5 & Diazepam 4 & - & 0 & - & $\mathrm{R}$ \\
\hline \multirow[t]{3}{*}{ One-way ANOVA } & $\mathrm{F}$ & & 431.2 & 27.67 & 49.34 & \\
\hline & $\mathrm{df}$ & & 3,12 & 4,16 & 3,12 & \\
\hline & $\mathrm{P}$ & & $<0.01$ & $<0.01$ & $<0.01$ & \\
\hline
\end{tabular}

$\mathrm{n}=5$ in each group; all the values were expressed in mean \pm SEM. ${ }^{\mathrm{a}} \mathrm{p}<0.01$ is significant when compared with control (ANOVA followed by Dunnett's multiple comparison test). PTZ: Pentylenetetrazol, EEAC: Ethanolic extract of A. calamus, Acorus calamus: A. calamus

In PTZ model, there was increase in the latency to the occurrence of convulsions in the three test groups $(100,200$, and $400 \mathrm{mg} / \mathrm{kg})$ of EEAC as compared to the control group, but it did not abolish the convulsions completely as was seen with the standard group of diazepam $(4 \mathrm{mg} / \mathrm{kg})$, but the increase in the latency was highly significant $(<0.01)$ in a dosedependent manner [Table 2].

All the animals recovered from the convulsions after the test and there were no deaths in any of the groups.

\section{DISCUSSION}

The present study was undertaken to evaluate the anticonvulsant activity of the EEAC in experimental animal models.

The following experimental designs were selected.

1. MES model

2. PTZ-induced seizure model.

The MES-induced convulsions for the screening of the anticonvulsant drug are the standard experimental model for evaluating a drug in experimental animals for its anticonvulsant property, which represents grand mal epilepsy in human beings.

The anticonvulsant effect by the MES model is determined by the effect of the drug in the tonic hind limb extensor phase of the convulsion, by either completely abolishing it or by reducing its duration. In the present study, it was found that the duration of the extensor phase in the test groups was reduced.

There was complete abolition of extensor phase in the standard group of phenytoin. Phenytoin sodium exerts antiepileptic effect by stabilization of neuronal membrane and thus prolongation of recovery of inactivated sodium channels. In high doses, phenytoin can also block the calcium influx during depolarization [18].

From the above findings, it can be said that the EEAC reduced the extensor phase of convulsion in a dose-dependent manner

The seizure produced by the PTZ-induced seizure model resemble to the absence or petit mal seizure in human beings. A drug, which causes either delay or complete abolition of convulsions in the PTZinduced seizure model, is said to have got anticonvulsant activity. It is reported to act through benzodiazepine receptor mechanisms in the brain.

In the present study, latency to convulsion increases in the test groups with increasing doses. In the standard group of diazepam ( $4 \mathrm{mg} / \mathrm{kg}$ ), there was complete absence of convulsions within the specified time of 60 min of observation after subcutaneous PTZ injection. Furthermore, the average duration of convulsions was decreased in test groups with increasing dose.

\section{CONCLUSION}

From the above two seizure models of MES and PTZ, it can be concluded that EEAC has got anticonvulsant effect in a dose-dependent manner.

\section{AUTHORS' CONTRIBUTION}

Dr. Shipra Kaushik contributed in drafting of protocol, conducting the experiment, collection, and analysis of data, drafting of the manuscript under the guidance of Dr. Kalpana Gohain. Both the authors read and approve the final manuscript.

\section{CONFLICTS OF INTEREST}

Nil.

\section{REFERENCES}

1. Fisher RS, Acevedo C, Arzimanoglou A, Bogacz A, Cross JH, Elger CE, et al. Ilae official report: A practical clinical definition of epilepsy. Epilepsia 2014;55:475-82

2. Fisher RS, van Emde Boas W, Blume W, Elger C, Genton P, Lee P, et al. Epileptic seizures and epilepsy: Definitions proposed by the international league against epilepsy (ILAE) and the international bureau for epilepsy (IBE). Epilepsia 2005;46:470-2

3. Reddy DS, Kuruba R. Experimental models of status epilepticus and neuronal injury for evaluation of therapeutic interventions. Int J Mol Sci 2013;14:18284-318.

4. Castel-Branco MM, Alves GL, Figueiredo IV, Falcão AC, Caramona MM. The maximal electroshock seizure (MES) model in the preclinical assessment of potential new antiepileptic drugs. Methods Find Exp Clin Pharmacol 2009;31:101-6.

5. Sarma P, Bhattacharya A. Models of epilepsy used in antiepileptic drug discovery. Int J Pharm Pharm Sci 2014;6:1-7.

6. Vyawahare NS, Khandelwal AR, Batra VR, Nikam AP. Herbal anticonvulsants. J Herb Med Toxicol 2007;1:9-14.

7. Online Archive of Wikipedia, The Free Encyclopedia (Internet) USA: Wikipedia Foundation, Inc. Available from: http//www.en. Wikipedia. Org / wiki/ Acorus calamus. [Last cited on 2012 Oct 15].

8. Suba V, Murugesan T, Rao RB, Pal M, Subhash C, Mandal BP. Neuropharmacological profile of Barleria lupulina Lindl. Extract in animal models. J Ethnopharmacol 2002;81:251-5.

9. Meena AK, Rao MM, Singh A, Kumari S. Physiochemical and preliminary phytochemical studies on the rhizome of Acorus calamus Linn. Int J Pharm Pharm Sci 2010;2:130-1.

10. Mukherjee PK, Kumar V, Mal M, Houghton PJ. Acorus calamus: Scientific validation of ayurvedic tradition from natural resources. Pharm Biol 2007;45:8(651-66).

11. The Chemist and Druggist. Extracta Liquida. Pharmaceutical Formulas PF. $11^{\text {th }}$ ed., Vol. 1. London: The Chemist and Druggist; 1950. p. 183-6.

12. OECD Guideline (Organization for Economic Corporation and Development).OECD Guidelines for Testing of Chemicals. France: OECD publishing; 2006 July 11. Section 4, Health Effects; Test no.425; Acute Oral Toxicity; Up and Down Procedure (adopted 2006 March 23, cited 2008 September); p. 1-27. Available from: http:// www.oecdbookshop.org/oecd/index. [Last accessed on 2011 Aug 02] 
13. Ghosh MN. Toxicity studies. In: Fundamentals of Experimental pharmacology. $5^{\text {th }}$ ed. Kolkata, India: Hilton and Company; 2008. p. 173-8.

14. Das S, Sarma P. A study on the anticonvulsant and antianxiety activity of ethanolic extract of Punica granatum Linn. Int J Pharm Pharm Sci 2014;6:389-92.

15. Kulkarni SK. Experiments on intact preparations. Pharmacology of CNS. Hand book of Experimental Pharmacology. $3^{\text {rd }}$ ed Reprint. New Delhi: Vallabh Prakashan; 2005. p. 131-9.
16. Vogel HG. Psychotropic and neurotropic activity. Drug Discovery and Evaluation, Pharmacological Assays. $2^{\text {nd }}$ ed. Berlin: Springer; 2002. p. 401-94.

17. McLean MJ, Macdonald RL. Multiple actions of phenytoin on mouse spinal cord neurons in cell culture. J Pharmacol Exp Ther 1983;227:779-89.

18. Kulkarni SK. Experiments on intact preparations. Pharmacology of CNS. Practical Pharmacology and Clinical Pharmacy. $1^{\text {st }}$ ed. New Delhi: Vallabh Publications; 2008. p. 130-59. 